\title{
Helper-dependent adenoviral vectors in experimental gene therapy
}

\author{
Alicja Józkowicz ${ }^{\bowtie}$ and Józef Dulak \\ Department of Medical Biotechnology, Faculty of Biotechnology, Jagiellonian University, Kraków, Poland; \\ 凶e-mail: alicia@mol.uj.edu.pl
}

Received: 15 March, 2005; revised: 01 June, 2005; accepted: 30 June, 2005

available on-line: 04 August, 2005

\begin{abstract}
In the majority of potential applications gene therapy will require an effective transfer of a transgene in vivo resulting in high-level and long-term transgene expression, all in the absence of significant toxicity or inflammatory responses. The most efficient vehicles for delivery of foreign genes to the target tissues are modified adenoviruses. Adenoviral vectors of the first generation, despite the high infection efficacy, have an essential drawback: they induce strong immune response, which leads to short term expression of the transgene, and limits their usefulness in clinical trials. In contrast, helper-dependent adenoviral vectors (HdAd) lacking all viral coding sequences display only minimal immunogenicity and negligible side-effects, allowing for longterm transgene expression. Thus, HdAd vehicles have become the carrier of choice for adenoviral vector-mediated experimental gene therapy, effectively used in animal models for delivery of transgenes into the liver, skeletal muscle, myocardium or brain. Strong and long-lasting expression of therapeutic genes has allowed for successful treatment of dyslipidemias, muscular dystrophy, obesity, hemophilia, and diabetes. Additionally, the large cloning capacity of HdAd, up to $37 \mathrm{~kb}$, facilitates the use of physiologically regulated, endogenous promoters, instead of artificial viral promoter sequences. This enables also generation of the single vectors expressing multiple genes, which can be potentially useful for treatment of polygenic diseases. In this review we characterize the basic features of HdAd vectors and describe some of their experimental and potential clinical applications.
\end{abstract}

Keywords: gene therapy, adenoviruses, helper-dependent adenoviral vectors

\section{ADENOVIRUSES}

Adenoviruses are non-enveloped doublestranded DNA viruses of 60-90 nm diameter. They can cause relatively mild, self-limiting diseases of the upper respiratory tract ("colds"), gastroenteritis, or conjunctivitis, but most infections are asymptomatic. Importantly, adenoviruses have not been associated with any neoplastic disease in humans (Benihound et al., 1999). The natural targets for adenoviruses are epithelial cells of the respiratory and gastrointestinal tracts. Following systemic intravenous injection, however, the viruses are preferentially cleared by the liver, which leads to highly efficient infection of both hepatocytes and liver endothelial cells (Chan, 1995).

Uptake of the adenovirus particle is a two stage process involving an initial interaction of the fiber protein with a range of cellular receptors, which include the coxsackievirus-adenovirus receptors (CAR) and major histocompatibility complex (MHC) class I (Bergelson et al., 1997). Then, the penton base protein binds to the $\alpha \mathrm{v}$-containing integrins allowing internalization via receptor-mediated endocytosis (Wickham et al., 1993). The toxic activity of pentons is also responsible for the rupture of the phagocytic membrane and release of the virus into the cytoplasm. Partially uncoated particles migrate to the nucleus, where the DNA enters through nuclear pores, whereupon it is converted into a virus DNA-cell histone complex. Viral DNA does not integrate into cell chromosomes (Mountain, 2000).

After infection with adenoviruses, an immune response rapidly develops. First, neutrophil and macrophage infiltration occurs and presentation of exogenous capsid antigens by MHC-II molecules activates $\mathrm{T}$ helper (Th) lymphocytes of both

^Presented at the International Review Conference on Biotechnology, Vienna, Austria, November 2004.

Abbreviations: AAV, adeno-associated viruses; apo, apolipoprotein; CTL, cytotoxic T lymphocyte; DMD, Duchenne muscular dystrophy; HdAd, helper-dependent adenoviral vectors; ITR, inverted terminal repeat. 
Th1 and Th2 phenotype, driving the cytotoxic and humoral responses, respectively. Then, MHC-I-restricted, cytotoxic T lymphocytes (CTL) trigger the specific immunoclearance of the infected cells (Kovesdi et al., 1997; Benihound et al., 1999). As a consequence of infection, low levels of IgG immunoglobulins against adenoviral antigens are sustained in the blood, which dramatically enhances the response against virus particles during the next infection (Kafri et al,. 1998). Of importance, the majority of the human population will have experienced at least one infection by age 10 and about $80 \%$ of adults have preexisting antibodies against adenoviruses (Eto et al., 2004).

\section{ADENOVIRAL VECTORS OF THE FIRST GENERATION}

The genome of adenoviruses consists of $36 \mathrm{~kb}$ of double-stranded linear DNA with inverted terminal repeat (ITR) sequences at each end. Expression of genes occurs in two phases, early and late, defined by the onset of DNA replication (Benihound et al., 1999). Early genes are encoded by four distinct transcription units, E1-E4, whereas the late gene products are generated from a single promoter. Importantly, proteins encoded by E1 region are indispensable for further viral gene expression and DNA replication (Wang \& Huang, 2000).

Vector of the first generation is prepared by substitution of a transgene in the place of E1 (or E1 and E3) genes (Fig. 1). The resulting construct has a cloning capacity up to $9 \mathrm{~kb}$. An E1-deficient $(\Delta \mathrm{E} 1)$ vector is replication-defective and must be propagated in a permissive cell line, engineered to provide E1 functions in trans (Chan, 1995; Gerard \& Chan, 1996). Substitution for the E3 genes is not necessary, as they are involved in inhibition of host immune antiviral response, not in the replication of the adenoviral genome. Among the 51 human adenovirus
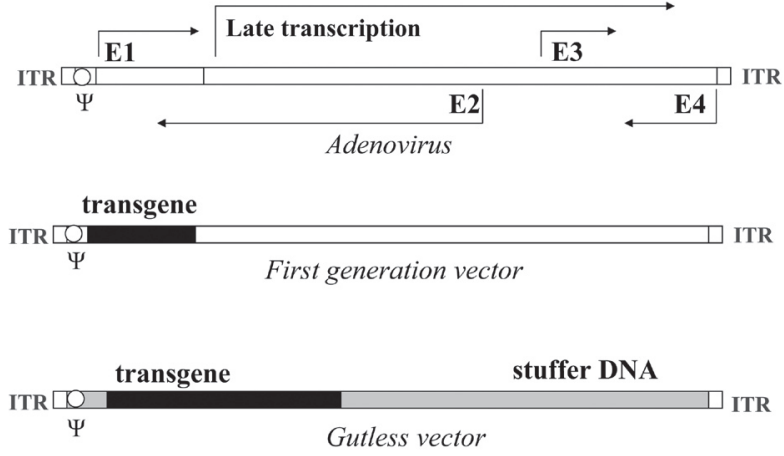

Figure 1. Scheme of the adenovirus, first generation adenovirus and gutless adenovirus genomes.

Viral sequences are depicted in white. ITR, inverted terminal repeats, necessary for genome propagation; $\Psi$, packaging sequence. After Józkowicz et al. (2002), modified. serotypes discovered to date, Ad5 and Ad2 are most commonly used for generation of vectors (Wang \& Huang, 2000).

Adenoviral vectors give the most efficient gene transfer in comparison with other systems (Mountain, 2000). Moreover, they can transduce both dividing and post-mitotic cells of nearly all human tissues - including skin, muscle, blood vessel, bone, nerve, and liver (Benihound et al., 1999; Mountain, 2000). They can be also effective in delivering genes into some leukocytes (Buttgereit et al., 2000). Following delivery, transgene expression is at a very high level. Unfortunately, it decreases rapidly after several days, being low or undetectable after several weeks (Mountain, 2000).

Many studies have clearly demonstrated that adenoviral vectors of first generation induce innate and adaptive immune responses in vivo against viral capsids and transduced cells (Wilmott et al., 1996; Muruve et al., 2004). Despite the deficiency in the E1 region, the vectors are, in fact, not completely replication-defective (Zhang et al., 1998). They deliver the transgene along with the residual viral genes and indeed synthesize some viral proteins (Dai et al., 1995). Even low level expression of these leads to activation of CTL and results in destruction of expressing cells, being the major cause of transgene silencing (Mountain, 2000).

\section{HELPER-DEPENDENT ADENOVIRUS VECTORS (HdAd)}

Helper-dependent adenoviral vector (HdAd), called also "gutless" or "gutted" vector, is created by removing all viral genes and leaving only the ITRs necessary for vector propagation, and the $\Psi$ sequence required for packaging (Fig. 1) (Mitani et al., 1995; Kochanek et al., 1996; Parks et al., 1996). Any unused space is occupied by a transgene or by noncoding "stuffer" DNA sequence, to build the vector to a size suitable for packaging (Hardy et al., 1997) (Fig. 1). This strategy completely eliminates the production of viral proteins in infected cells. Therefore, HdAd elicits only minute or negligible CTL response and is capable of producing long-term gene expression (Morral et al., 1998; Morsy et al., 1998a). Additional advantage of HdAd is a high cloning capacity, extended up to $37 \mathrm{~kb}$ (Mitani et al., 1995).

The nature of the DNA backbone can have important effects on the functioning of the HdAd virus, which must be taken into account in the design of vectors. The most commonly used stuffer DNA originates from human hypoxanthine-guanine phosphoribosyltransferase (HPRT) (Parks et al., 1999).

The first step in generation of HdAd constructs is based on ligation of the expression cassette into large plasmids containing the viral ITRs flank- 
ing stuffer DNA. This process, although commonly applied, is generally very inefficient. It has been shown, however, that similarly as in the case of the $\Delta \mathrm{E} 1$ adenoviral vectors, plasmids for generation of HdAd constructs can be obtained by homologous recombination in Escherichia coli, which potentially can facilitate the production (Toietta et al., 2002).

A number of systems have been also developed for rescuing HdAd. The most common method for propagation and purification of $\mathrm{HdAd}$ utilizes two elements: i) a helper virus $(\Delta \mathrm{E} 1 / \Delta \mathrm{E} 3)$ with $\Psi$ sequence flanked by loxP sites (Fig. 2) and ii) a modified 293cre cell line expressing Cre recombinase which catalyzes recombination between loxP sequences, excising the packaging site from helper DNA. Such a deletion renders the helper genome unpackagable but leaves all other viral functions intact, retaining the ability to replicate and provide helper functions (Fig. 3) (Parks et al., 1996; Hardy et al., 1997). The efficacy of this technology is sufficient for experimental gene therapy, but is not suitable for production and purification of HdAd vectors at a scale necessary for clinical use (Sakhuja et al., 2003). To increase the efficiency of the system, both improved helper viruses and alternative gutless vector producer cell lines are necessary. One of the promising modifications is establishing the cells adapted to serum-free suspension culture, which can allow obtaining high-titer gutless vector preparations by using bioreactor technology (Sakhuja et al., 2003; Palmer \& Ng, 2005).

An additional problem to be solved is contamination with helper $\Delta \mathrm{E} 1$ virus, which may have substantial unwanted effects. Unfortunately, a helper virus, even lacking a packaging signal, still can be packaged, although at a low frequency (about 0.1\%) (Sakhuja et al., 2003). It seems that this level of impurity cannot be further decreased using the Cre/ loxP system, as Cre recombinase in 293cre cells per-

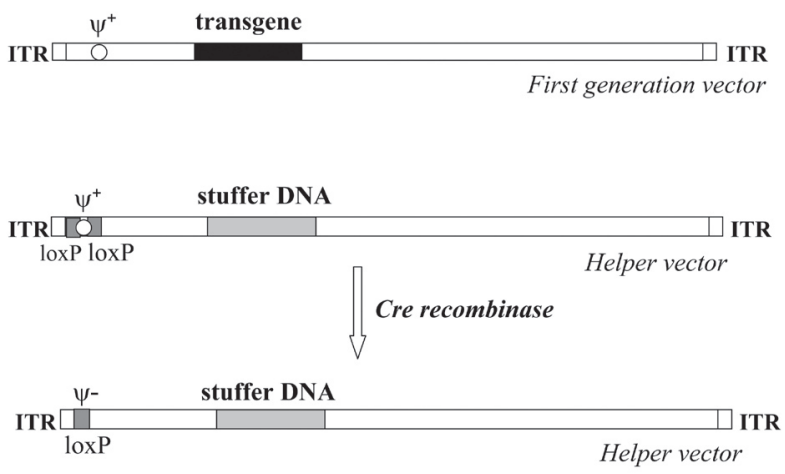

Figure 2. Schematic comparison of the first generation adenoviral vector and helper vector.

Note that in the helper genome the transgene is replaced by stuffer DNA, while the packaging sequence $\Psi$ is flanked by loxP sites. In the presence of recombinase cre, $\Psi$ is excised from the helper genome. mits some helper viruses to escape packaging signal excision and propagate ( $\mathrm{Ng}$ et al., 2002). Thus, the resulting viral stocks must be additionally purified by ultracentrifugation in $\mathrm{CsCl}$, which can produce HdAd stocks with very low (less than $0.01 \%$ ) helper contamination (Hardy et al., 1997).

This separation step hinders, however, largescale production of clinical-grade $\mathrm{HdAd}$ virus. One of the possible solutions is using a more efficient recombinase, e.g. modified FLP (FLPe), to remove $\Psi$ from the helper virus in the producer cells. FLP has been shown to mediate maximum levels of excision close to $100 \%$ compared to $80 \%$ for Cre. Thus, it as postulated that the FLPe-based system may yield HdAd with very low levels of helper virus contamination without the need for ultracentrifugation, which should allow large-scale generation of gutless vectors by means of column chromatography (Umana et al., 2001). Finally, the safety of the HdAd vectors can be further optimized by using doubledeleted $\Delta \mathrm{E} 1 \Delta \mathrm{E} 2 \mathrm{a}$ helper virus (Zhou et al., 2001).

Gutless adenoviruses can infect a wide range of mammalian tissues, independent of the replicative state of the cells. Like $\Delta \mathrm{E} 1$ particles, intravenously injected HdAd vectors transport the transgene preferentially to the liver, where infection efficacy may reach almost $100 \%$. After local injection, however, they can ensure efficient expression in other organs as well (Bramson et al., 2004; Palmer \& Ng, 2005). Nevertheless, certain serotypes of adenoviruses have diverse tissue tropisms in vivo, and in some tissues, e.g. in skeletal muscles, the efficacy of adenoviral vectors is relatively low. Particularly resistant are some lymphoid cells (Bramson et al., 2004). This dis-

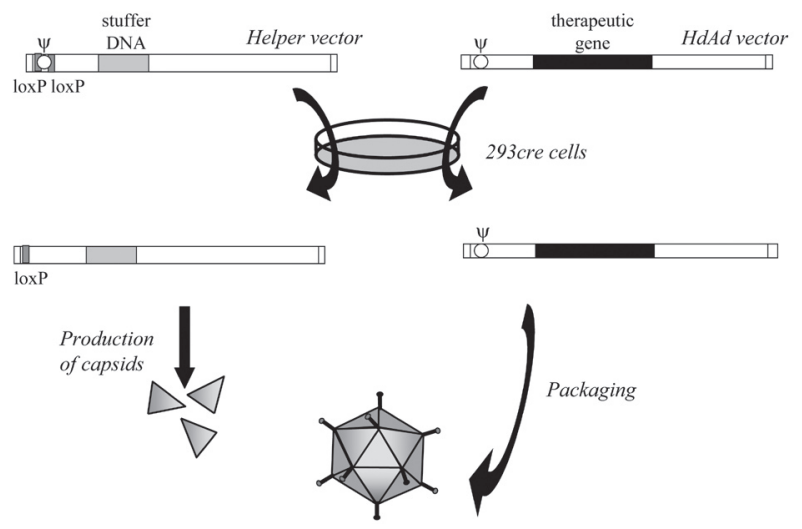

Figure 3. Production of helper-dependent adenoviruses using cre-loxP system.

After cotransfection of 293cre cells with genomes of the helper vector and helper-dependent vector, viral proteins necessary for genome replication and capsid formation are produced by helper virus. However, in the presence of recombinase cre the $\Psi$ sequence, flanked by loxP sites, is removed from the helper genome. Therefore, only $\mathrm{HdAd}$ DNA can be packaged into viral capsids. After Parks et al. (1996), simplified. 
advantage can be overcome through modification of adenovirus fiber composition. For example, a chimeric Ad5/Ad35 fiber incorporated into an HdAd construct augmented the infection of K562 lymphoid cells approx. 50 times (Balamotis et al., 2004), whereas incorporation of a polylysine motif resulted in a $60-70 \%$ increase in transduction efficiency in adult skeletal muscles (Bramson et al., 2004).

In the liver, expression of the transgene is limited to several weeks with $\Delta \mathrm{E} 1 \mathrm{Ad}$ vectors (Morral et al., 1999). In contrast, single delivery using HdAd may result in a strong expression lasting for longer than a year or even 2.5 years, as shown in baboons and mice, respectively (Morral et al., 1999; Kim et al., 2001). Furthermore, some studies have demonstrated the feasibility of circumventing the humoral response to the virus by sequential injection with vectors of different serotypes. These observations suggest that very long-term expression should be possible by re-administration of the transgene using different HdAds (Morral et al., 1999; Kim et al., 2001).

It has been postulated that recombinant adenoviral vectors have some mechanism ensuring their persistence during cell cycling. When rapid hepatocyte cell divisions in mouse liver were induced by partial hepatectomy, a 55\% reduction in transgene expression from an HdAd vector was observed after one month. In contrast, in plasmid DNA-injected mice it decreased by 95\% (Ehrhardt et al., 2003). Nevertheless, expression of a transgene delivered by either $\Delta \mathrm{E} 1 \mathrm{Ad}$ or $\mathrm{HdAd}$ vectors is transient in proliferating cells, since such vectors do not possess elements that allow replication and segregation of the replicated genomes to daughter cells (Kreppel \& Kochanek, 2004).

In contrast to adenoviral systems, EpsteinBarr virus (EBV) episomes are stably maintained in permissive proliferating cell lines due to EBV nuclear antigen 1 (EBNA-1)-mediated replication and segregation. Thus, to achieve sustained transgene expression in proliferating cells, a binary HdAd-EBV hybrid system has been developed that consists of one HdAd vector for the expression of recombinase and a second HdAd vector that harbors all of the sequences for the EBV episome, containing the transgene and EBNA-1 expression cassettes, flanked by recombinase-recognized sites. Upon coinfection of cells, the EBV episomes are circularized by recombinase expressed from the first vector. Such hybrid viruses have about $40 \%$ infection efficacy in vitro (Dorigo et al., 2004). Depending on the system, up to $98 \%$ of the circularized genomes are replicated and segregated to daughter cells, and transgene expression in proliferating cells can be observed for over 20 weeks (Dorigo et al., 2004; Kreppel \& Kochanek, 2004). This novel gene transfer system may have the potential to confer long-term episomal transgene expression and therefore to correct genetic defects with reduced vector-related toxicity and without the risk of insertional mutagenesis (Dorigo et al., 2004).

Furthermore, adenoviral vectors randomly integrate into host chromosomes at frequencies of $0.001-1 \%$ of infected cells, and gene expression from the integrated vector persistes for at least 50 cell divisions (Harui et al., 1999; Mitani \& Kubo, 2002). Of note is that even extensive homologies and abundant chromosomal repeat elements present in the vector backbone did not lead to integration of the transgene expression cassette via homologous or homology-mediated mechanisms (Hillgenberg et al., 2001).

To improve the integration frequencies, a variety of hybrid vectors combining the highly efficient DNA delivery of HdAd adenovirus with the integrating machinery of transposons, retroviruses, and adeno-associated viruses (AAV) have been emerging. These hybrid vectors have shown promise, at least in in vitro systems (Mitani \& Kubo, 2002). For example an HdAd-transposon hybrid vector has proven useful in sustaining stable expression of a transgene through integration into host cell chromosomes. Systemic in vivo delivery of this system, which utilizes a donor Sleeping Beauty (SB) transposon vector that undergoes FLP-mediated recombination, resulted in efficient generation of transposon circles and stable SB transposase-mediated chromosomal integration in mouse liver. Somatic integration was sufficient to maintain therapeutic levels of human coagulation Factor IX for more than six months in mice undergoing extensive liver proliferation (Yant et al., 2002).

Similarly, a chimeric system combining HdAd vector and L1 retrotransposon has been elaborated. Efficient adenovirus-mediated delivery of the L1 element into cultured human cells resulted in subsequent retrotransposition and stable integration of the transgene (Soifer et al., 2001; Soifer \& Kasahara, 2004). Another possibility is employing an HdAd virus as a carrier to deliver a genome of fully functional retroviral vector. This experimental system can transduce the cells with permanent integration and progressive spread of transgene expression (Soifer et al., 2002).

Finally, HdAd viruses can be used to deliver an expression cassette together with the Rep68/78 gene or AAV-ITRs, two elements which are necessary for integration into an AAV specific locus of human chromosome 19 (AAVS1). Despite the low efficacy of vector rescue, DNA integration at the AAVS1 site was demonstrated in hepatoma cells coinfected with HdAd expressing Rep78 and with the second HdAd vector carrying a transgene flanked by AAVITRs. The high transduction efficiency, large cloning capacity, and high titer of $\mathrm{HdAd}$, combined with the site-specific integration machinery provided by the AAV-derived components, can make the Ad/AAV hybrid viruses a promising vehicle for gene therapy (Recchia et al., 1999). 


\section{IMMUNOLOGICAL RESPONSE TO ADENOVIRAL VECTORS}

Gutless adenoviruses display strongly reduced toxicity and immunogenicity compared to early generation vectors (Sakhuja et al., 2003). Especially, a CTL-mediated response, very strong in the case of $\Delta \mathrm{E} 1$ carriers, is usually negligible (Morral et al., 1998; Morsy et al., 1998a). It must be stressed, however, that high doses of $\Delta \mathrm{E} 1$ viruses cause longterm hepatotoxicity not only due to viral gene expression from the vector backbone, but also an acute innate inflammatory reaction in response to the capsid proteins (Brunetti-Pierri et al., 2004).

Intravascular injection of adenoviral vectors may result in a toxic and potentially lethal reaction, the mechanism of which is poorly understood (Schiedner et al., 2003). It can induce early expression of inflammatory cytokine and chemokine genes in the liver, including interferon-inducible protein-10 (IP-10), macrophage inflammatory protein-2 (MIF$2)$, interleukin-6 (IL-6) and tumor necrosis factor- $\alpha$ (TNF $\alpha$ ), leading to the recruitment of CD11b-positive leukocytes to the transduced liver within hours of administration (Muruve et al., 2004; Mok et al., 2005). Furthermore, systemic delivery of adenoviral vectors in mice may lead within minutes to a transient change in behavior that is characterized by inactivity and lethargy. Accordingly, immediately after injection a significant drop in blood pressure can be measured probably due to the systemic activation of endothelial cells and increased production of nitric oxide (NO), resulting from activation (followed by destruction) of Kupffer cells (Schiedner et al., 2003). This acute toxicity is neither prevented nor reduced for HdAd, as the capsid composition and structure remains unchanged (Stilwell et al., 2003; BrunettiPierri et al., 2004). Recent data have demonstrated, however, that polyethylene glycol (PEG) modification of adenovirus can protect $\mathrm{HdAd}$ vectors from preexisting immune responses by reducing protein-protein interactions. The reduced innate reaction paralleled similar reductions in vector uptake by Kupffer cells (Mok et al., 2005).

\section{COMPARISON OF HdAd AND $\triangle \mathrm{E} 1$ ADENOVIRUSES}

HdAd vehicles have been tested in several animal models, with very promising results. The most convincing evidence of superiority of $\mathrm{HdAd}$ vectors over other types of adenoviral vehicles is supplied by a direct comparison of therapeutic benefits resulting from delivering the same gene using different vector systems. For example, in experiments performed in mice, a systemic intravenous injection of erytropoietin gene using $\mathrm{HdAd}$ vector produced a 100-fold higher expression per infectious particle when compared to a first generation virus. The expression was long-lasting and resulted in a significant increase in hematocrit for more than six months (Maione et al., 2000). Also comparing to a $\Delta \mathrm{E} 1 / \Delta \mathrm{E} 2 \mathrm{a} / \Delta \mathrm{E} 3$ vector, the gutless adenovirus produced ten-fold higher and much longer expression of factor VIII (FVIII) in hemophilia-A mice (Reddy et al., 2002). Finally, a study on the duration of expression of the $\alpha_{1}$-antitrypsin (hAAT) gene delivered to the liver of baboons has demonstrated that administration of HdAd resulted in transgene expression for longer than a year in comparison to three months obtained from first generation vehicles (Morral et al., 1999).

Similar differences were also observed when $\mathrm{HdAd}$ and $\Delta \mathrm{E} 1$ vectors, both coding for urokinase plasminogen activator (uPA), were delivered locally into the carotid artery in rabbits. The expression of uPA was lost, and vector DNA declined rapidly in arteries infused with first generation vehicles, whereas it persisted for at least two months in HdAd-treated vessels. Moreover, these arteries had significantly less inflammation and neointimal formation than the vessels treated with the $\Delta \mathrm{E} 1$ adenoviruses (Wen et al., 2004). Considerably weaker inflammation was also found in the rat myocardium injected with HdAd, as illustrated by less abundant infiltrates of macrophages or lymphocytes and by reduced levels of pro-inflammatory cytokines. Thus, gutless vectors may be superior to earlier-generation adenovirus vectors for cardiovascular gene therapy (Fleury et al., 2004).

\section{LOCAL INJECTIONS OF HdAd VECTORS}

After local injection, gutless vectors can provide efficient expression in many tissues, e.g. in skeletal muscles. It has been found that low doses of HdAd can direct long-lasting gene expression in the muscles of mice, with $100 \%$ of treated animals showing sustained expression after 4 months. Moreover, this route of gene delivery can be also used in the presence of a preexisting immunity to adenovirus. This suggests that gene therapy by intramuscular delivery of HdAd vectors is feasible (Maione et al., 2001).

The toxicity and immunogenecity of first generation adenoviral vectors prohibited the application of gene transfer in the majority of central nervous system disorders. Zou and colleagues (2000; 2001) compared the effect of injection of $\Delta \mathrm{E} 1$ and $\mathrm{HdAd}$ adenoviral vectors into the brain of adult rats. They found that first generation vector-mediated gene expression decreased rapidly, becoming undetectable after 1-2 months, while expression from $\mathrm{HdAd}$ persisted for more than half a year. In addition, in 
contrast to the effects of $\Delta \mathrm{E} 1$ vectors, secretion of proinflammatory cytokines was minimal after $\mathrm{HdAd}$ vector injection, resulting in reduced numbers of activated microglial cells, astrocytes, and infiltrating macrophages in brain tissue. These findings indicate that HdAd vehicles should provide a safe and effective means to transfer therapeutic genes into the brain (Zou et al., 2000; 2001).

Notably, recent study has shown that helper-dependent canine adenovirus $(\mathrm{CAV}-2)$ vectors can preferentially transduce neurons and efficiently travel via axonal retrograde transport. One year after striatal injections into the rat brain, a stable high level of transgene expression was found in neurons of the striatum, substantia nigra, and in the basal nuclei of Meynert. This suggests that helper-dependent CAV-2 vectors may be clinically relevant for the treatment of many neurodegenerative diseases (Soudais et al., 2004).

\section{SPECIFIC OR REGULABLE PROMOTERS}

The ability to target specific tissues is important in many applications of gene therapy. In this respect, a disadvantage of adenoviral vectors is the relative lack of specificity with which they transduce cells. One approach to overcome this is to express the therapeutic gene under the control of a tissuespecific promoter. However, the specificity and activity of such promoters may be altered by the adenoviral sequences in the vector backbone (Shi et al., 2002). In contrast to the first generation adenoviruses, HdAd does not contain any cis-acting viral sequences which could interfere with the specificity of the inserted promoters (Shi et al., 2004). Accordingly, direct comparison has evidenced that ligand-inducible transcriptional regulation systems act much better in the context of gutless adenoviruses than in the vectors of earlier generations (Shi et al., 2002; Zerby et al., 2003).

Gutless vectors are also suitable to delivering a transgene regulated by ligand-inducible sequences. For example, in mice injected with an HdAd vector containing the interferon- $\alpha$ (IFN $\alpha$ ) gene under control of a tetracycline inducible transactivator, high levels of serum IFN $\alpha$ appeared only after transcriptional activation. Furthermore, it was efficiently reinducible to the same high level up to 3 months post injection, and the amount of expressed cytokine could be regulated by dosing doxycycline. Of importance, such a treatment resulted in prolonged survival and reduced liver damage in mice challenged with a lethal dose of coronavirus (Aurisicchio et al., 2001).

Similarly, systemic injection of HdAd viruses containing an RU486-inducible system for liver-specific generation of interleukin-12 (IL-12) resulted in expression of the transgene only in the liver of mice, despite the presence of the vector in many different tissues. Furthermore, the RU486-induced synthesis of IL-12 caused a complete regression of liver metastases in all animals treated. Thus, gutless adenoviral vectors allowing liver-specific and regulable transgene expression for prolonged periods of time can be promising tools for gene therapy of liver cancer and could also be useful for other forms of hepatic diseases (Wang et al., 2004).

Finally, some promoters can be used to drive the transgene expression specifically in tumor cells. It has been shown, for instance, that the promoter of secretoglobin family 2A member 2 (SCGB2A2, also known as mammaglobin-1) is highly and preferentially active in breast cancer cells when introduced via an HdAd vector. This system could be, perhaps, particularly advantageous for transfer of toxic genes to mammary tumors (Shi et al., 2004).

\section{HdAd IN TREATMENT OF DISEASES IN ANIMAL MODELS}

Currently HdAd vectors are being tested in experiments determining the potency of gene therapy strategies in preventing and treatment of inherited diseases in animal models.

Several experiments focused on hemophilia caused by deficiency of Factor VIII (FVIII) or Factor IX (FIX). Many different approaches via gene transfer have been attempted in animal models but all have potential drawbacks (Ehrhardt et al., 2003). Methods based on $\Delta \mathrm{E} 1$ adenoviruses have been ineffective primarily due to the immunogenicity of these vectors (Brown et al., 2004b). On the contrary, HdAd vectors have produced hemostatic correction in animal models. In a dog with hemophilia-B, FIX plasma concentrations were sustained for up to 2.5 months at a therapeutic range and normalization of whole blood clotting time for about a month. This was followed by a decrease and stabilized partial correction for 4.5 months. In sharp contrast to other studies using earlier generations of adenoviral vectors, there was no vector-related elevation of liver enzymes, no fall in platelet counts, and liver histology was normal (Ehrhardt et al., 2003).

Similarly, in hemophilic mice treated with HdAd vectors harboring FIX or FVIII, high and sustained levels of therapeutic proteins were obtained in the serum, without or with minimal unwanted side-effects (Ehrhardt \& Kay, 2002; Reddy et al., 2002; Brown et al., 2004b). However, the first patient suffering from severe hemophilia-A to be treated with a gutless adenoviral vector expressing full-length FVIII, and who appeared to have an FVIII level onehundredth of the normal one for several months, developed a transient inflammatory response with 
hematologic and liver abnormalities (Chuah et al., 2004).

Several studies have also been devoted to the treatment of Duchenne muscular dystrophy (DMD), a lethal degenerative disease resulting from the absence of the dystrophin protein at the muscle membrane (Haecker et al., 1996; Kochanek et al., 1996).

Full-length dystrophin cDNA is too long to be accommodated in an adenoviral vector of the first generation. It can be easily introduced, however, to an HdAd vehicle. Experiments performed in mdx mice (animal model for DMD) evidenced high, local expression of dystrophin cDNA after intramuscular injection of an $\mathrm{HdAd}$ construct. The activity of the transgene was accompanied by restoration of dystrophin-associated cytoskeletal proteins and histological improvement of dystrophic muscle (Haecker et al., 1996; Kochanek et al., 1996; Dudley et al., 2004). Unfortunately, transgene expression was usually short-lasting (Kochanek et al., 1996). Possibly, the immune response induced by transgene protein was responsible for the loss of vector activity (Chen et al., 1997). This observation illustrates the general problem of supplementary gene therapy - where the transgene product (e.g., normal dystrophin protein), when introduced to an animal or patient deficient in the wild type gene, can be recognized as a potential target for immune responses (Haecker et al., 1996).

Interestingly, the success of therapy and the strength of immunological response may depend on the age of treated animals, as demonstrated in an elegant study where muscles of neonatal and juvenile $\mathrm{mdx}$ mice were injected with an $\mathrm{HdAd}$ vector encoding two full-length murine dystrophin cDNAs. At 10 days post-injection of neonatal muscles, $42 \%$ of the total number of fibers were dystrophin-positive, a value that did not decrease for at least 6 months. In treated juveniles, maximal transduction was lower (24\% of fibers), and it further decreased during 6 months. All the aspects studied of the physiology including maximal force-generating capacity and resistance to contraction-induced injuries were significantly improved in neonatally treated mice, whereas the therapeutic effects in the older animals were much worse. In both groups a strong humoral response against murine dystrophin was observed but a mild inflammatory response occurred only in the juveniles (Gilbert et al., 2003).

Local delivery of HdAd vectors may be also used to regulate angiogenesis, the formation of new blood vessels from preexisting capillaries. For example, subretinal injection of a gutless adenovirus containing an expression construct for angiopoietin2 (Ang2) was able to perturb retinal pigmented epithelial (RPE) cells and, together with overexpression of vascular endothelial growth factor (VEGF), induce choroidal neovascularization (Oshima et al., 2004).
Accordingly, subretinal injection of an HdAd vehicle designed to provide expression of endostatin, an endogenous inhibitor of angiogenesis, significantly decreased vascular leakage induced by overexpression of VEGF. Thus, one can suppose that in patients with diabetic retinopathy, endostatin gene transfer by a gutless vector may provide a way to decrease the risk of the major causes of visual loss: macular edema, neovascularization, and retinal detachment (Takahashi et al., 2003).

Promising results have also been obtained with correction of leptin disorders. Leptin is a potent modulator of food intake and its deficiency leads to uncontrolled appetite, obesity, and increased blood insulin and glucose levels (Campfield et al., 1995). Morsy and colleagues (1998b) compared the safety and efficacy of leptin delivery mediated by $\mathrm{HdAd}$ and a first generation vector in leptin-deficient mice. In contrast to a $\Delta \mathrm{E} 1$ virus, $\mathrm{HdAd}$ leptin delivery did not induce any liver toxicity, inflammation or cellular infiltrates, and resulted in prolonged elevation of serum leptin levels, leading to significant weight loss in the treated animals.

Gene therapy was also proposed as a potential approach for treatment of one of the most common urea cycle disorder, ornithine transcarbamylase (OTC) deficiency (Raper et al., 1998). Unfortunately, in the single human clinical trial using $\triangle \mathrm{E} 1$ adenovirus coding for the OTC gene one patient died after delivery of a high dose of the vector. Moreover, this trial did not show any biochemical correction in the 18 patients enrolled (Raper et al., 2003). In accordance, in OTC-deficient mice treated with $\Delta \mathrm{E} 1 / \Delta \mathrm{E} 2$ adenovirus expressing the OTC gene, the therapeutic effect was only transient (Ye et al., 1997). In contrast, a recent paper describes that $\mathrm{HdAd}$ vector was able to produce metabolic correction in mice for $>6$ months. This treatment resulted in normalized orotic aciduria, normal hepatic enzyme activity, and elevated OTC mRNA and protein levels in the absence of chronic hepatotoxicity. This may suggest potential usefulness of HdAd vehicles for treating human inborn errors of hepatocyte metabolism, like the urea cycle disorders, that require high-level transduction for clinical correction (Mian et al., 2004).

Since HdAd vectors have a natural tropism to the liver, they can be a very promising tool for gene therapies in inherited lipid metabolism disorders. Liver is a central organ in lipid regulation and transfer of a single gene involved in lipoprotein turnover could effectively interact with other key regulatory molecules (Gerard \& Collen, 1997).

One of the potential targets for HdAd vectormediated gene therapy is familial hypercholesterolemia $(\mathrm{FH})$, a disease resulting from low density lipoprotein receptor (LDLR) deficiency, which affects approx. 1 in 500 persons in the heterozygous state and 1 in one million persons in the homozygous 
state (St. Clair \& Beisiegel, 1997). A model of human FH are low density lipoprotein receptor (LDLR)-deficient mice. It has been shown that a low-dose HdAd vector harboring the LDLR gene efficiently protects $\mathrm{LDLR}^{-/}$mice from development of atherosclerosis for at least 60 weeks. At the same time, in control animals atherosclerosis lesions covered approx. 50\% of the surface of aortas. Moreover, the lipid-lowering effect of HdAd-LDLR lasted for at least 108 weeks ( $>2$ years), by which time all control mice had died. In addition to retarding lesion progression, the treatment caused lesion remodeling from a vulnerable-looking to a more stable-appearing phenotype (Nomura et al., 2004).

Another approach to correcting hypercholesteromia in $\mathrm{LDLR}^{-/}$mice employed a gutless vector encoding very light density lipoprotein receptor (VLDLR) (Oka et al., 2001). VLDLR binds apolipoprotein E (apoE) and can mediate the uptake of proatherogenic particles like chylomicrons and VLDL remnants, intermediate density lipoprotein (IDL) or lipoprotein-a (Lp(a)). VLDLR is present in many cell types, e.g. in skeletal muscle fibres, adipocytes, macrophages or foam cells, but it is not expressed in the liver (St. Clair \& Beisiegel, 1997). The superiority of VLDLR over the "natural" receptor (LDLR) was attributable to the fact that LDLR could be recognized as a neoantigen by LDLR-deficient mice, which mounted humoral and cellular immune response to the LDLR, leading to the extention of transgene expression. Ectopic liver expression of VLDLR did not induced any immune response (Kobayashi et al., 1996; Nomura et al., 2004). In effect, VLDLR gene therapy in LDLR-deficient mice produced a substantially more sustained hypocholesterolemic response than did LDLR: the lowering of plasma cholesterol lasted for at least 6 months and was associated with almost complete prevention of atherosclerosis (Oka et al., 2001).

Similar anti-atherosclerotic effects were also obtained after injection of $\mathrm{LDLR}^{-/-}$or apoE $\mathrm{E}^{-/-}$mice with an HdAd vector encoding apolipoprotein-AI (apoAI), the major protein component of high-density lipoproteins (HDL) (Belalcazar et al., 2003). Overexpression of apoAI increased HDL cholesterol and decreased atherosclerosis in the absence of detectable hepatic toxicity (Pastore et al., 2004).

The most spectacular outcome was achieved by Chan and coworkers (including one of us, A.J.), using a gutless adenovirus harboring apoE gene. ApoE-deficient mice, which display spontaneous hypercholesterolemia, were treated with a single injection of an HdAd vector expressing apoE at 12 weeks of age. This treatment normalized plasma apoE concentration and produced an immediate fall in plasma cholesterol to the values typical for wildtype mice, without any side-effects. Importantly, the correction lasted for at least 2.5 years, the natural life-span of the mice, and resulted in complete protection against atherosclerosis (Kim et al., 2001).

Finally, Chan and coworkers have demonstrated that HdAd can be used for the treatment of diabetes. Administration of a mixture of vectors coding for betacellulin and a pancreatic islet transcription factor, Neurod, into streptozotocin-treated mice, induced islet neogenesis in the liver, which completely reversed diabetes and normalized glucose level for at least four months (Kojima et al., 2003).

\section{CONCLUSIONS}

HdAd vectors give rise to long-term sustained transgene expression in both small laboratory animals and nonhuman primates. They are as efficient as the earlier generation adenoviral vehicles, but substantially less toxic. Thus, they appear to be one of the most promising tools for gene therapy, especially the therapy directed to the liver, skeletal muscle, brain, or cardiovascular system. The large insert capacity of the gutless vector allows for simultaneous expression of several genes, introduction of long cDNA (e.g., dystrophin) or genomic DNA, and addition of the long regulatory DNA regions preserving their cell-type specificities.

There are, however, some important pitfalls. Although gutless adenoviruses do not induce T lymphocyte-mediated cytotoxicity, their capsid, crucial for the efficient transgene delivery, contains all of the viral proteins being a potential target for neutralizing antibodies. Acute toxicity provoked by the capsid, especially after systemic, intravascular injection, is the most significant obstacle currently hindering clinical application. This immune response specific for the antigenic viral capsid proteins could not be alleviated to date. It seems, however, that local delivery of the vector or administration of PEGylated capsids can possibly allow one to bypass a preexisting humoral immunity and attenuate the acute toxicity. Thus, HdAd vectors, if used with caution, may have a great potential for efficient gene delivery both in experimental gene therapy and in clinical trials.

\section{Acknowledgements}

This paper was partially supported by grants from the Polish Ministry for Science and Information Society Technologies, No. 2P04 01626 and K096/P05/ 2004. A.J. is the International Senior Research Fellow of The Wellcome Trust.

\section{REFERENCES}

Aurisicchio L, Bujard H, Hillen W, Cortese R, Ciliberto G, La Monica N, Palombo F (2001) Regulated and prolonged expression of mIFN(alpha) in immunocompe- 
tent mice mediated by a helper-dependent adenovirus vector. Gene Ther 24: 1817-1825.

Balamotis MA, Huang K, Mitani K (2004) Efficient delivery and stable gene expression in a hematopoietic cell line using a chimeric serotype 35 fiber pseudotyped helperdependent adenoviral vector. Virology 324: 229-237.

Belalcazar LM, Merched A, Carr B, Oka K, Chen KH, Pastore L, Beaudet A, Chan L (2003) Long-term stable expression of human apolipoprotein A-I mediated by helper-dependent adenovirus gene transfer inhibits atherosclerosis progression and remodels atherosclerotic plaques in a mouse model of familial hypercholesterolemia. Circulation 107: 2726-2732.

Benihound K, Yeh P, Perricaudet M (1999) Adenovirus vector for gene delivery. Curr Opin Biotech 10: 440-447.

Bergelson JM, Cunningham JA, Droguett G, Kurt-Jones EA, Krithivas A, Hong JS, Horwitz MS, Crowell RL, Finberg RW (1997) Isolation of a common receptor for coxsackie B viruses and adenoviruses 2 and 5. Science 275: 1320-1323.

Bramson JL, Grinshtein N, Meulenbroek RA, Lunde J, Kottachchi D, Lorimer IA, Jasmin BJ, Parks RJ (2004) Helper-dependent adenoviral vectors containing modified fiber for improved transduction of developing and mature muscle cells. Hum Gene Ther 15: 179-188.

Brown BD, Shi CX, Powell S, Hurlbut D, Graham FL, Lillicrap D (2004a) Helper-dependent adenoviral vectors mediate therapeutic factor VIII expression for several months with minimal accompanying toxicity in a canine model of severe hemophilia A. Blood 103: 804810.

Brown BD, Shi CX, Rawle FE, Tinlin S, McKinven A, Hough C, Graham FL, Lillicrap D (2004b) Factors influencing therapeutic efficacy and the host immune response to helper-dependent adenoviral gene therapy in hemophilia A mice. J Thromb Haemost 2: 111-118.

Brunetti-Pierri N, Palmer DJ, Beaudet AL, Carey KD, Finegold M, Ng P (2004) Acute toxicity after high-dose systemic injection of helper-dependent adenoviral vectors into nonhuman primates. Hum Gene Ther 15: 35-46.

Buttgereit P, Weineck S, Ropke G, Marten A, Brand K, Heinicke T, Caselmann WH, Huhn D, Schmidt-Wolf IG (2000) Efficient gene transfer into lymphoma cells using adenoviral vectors combined with lipofection. Cancer Gene Ther 7: 1145-1155.

Campfield LA, Smith FJ, Guisez Y, Devos R, Burn P (1995) Recombinant mouse OB protein: evidence for a peripheral signal linking adiposity and central neural networks. Science 269: 546-549.

Chan L (1995) Use of somatic gene transfer to study lipoprotein metabolism in experimental animals in vivo. Curr Opin Lipidol 6: 335-340.

Chen HH, Mack LM, Kelly R, Ontell M, Kochanek S, Clemens PR (1997) Persistence in muscle of an adenoviral vector that lacks all viral genes. Proc Natl Acad Sci USA 94: $1645-1650$

Chuah MK, Collen D, VandenDriessche T (2004) Clinical gene transfer studies for hemophilia A. Semin Thromb Hemost 30: 249-256.

St. Clair RW, Beisiegel U (1997) What do all the apolipoprotein receptors do? Curr Opin Lipidol 8: 243-245.

Dai Y, Schwarz EM, Gu D, Zhang WW, Sarvetnic N, Verma IM (1995) Cellular and humoral immune responses to adenoviral vectors containing factor IX gene: tolerization of factor IX and vector antigens allows for longterm expression. Proc Natl Acad Sci USA 92: 1401-1405.

Dorigo O, Gil JS, Gallaher SD, Tan BT, Castro MG, Lowenstein PR, Calos MP, Berk AJ (2004) Development of a novel helper-dependent adenovirus-Epstein-Barr virus hybrid system for the stable transformation of mammalian cells. J Virol 78: 6556-6566.

Dudley RW, Lu Y, Gilbert R, Matecki S, Nalbantoglu J, Petrof BJ, Karpati G (2004) Sustained improvement of muscle function one year after full-length dystrophin gene transfer into mdx mice by a gutted helper-dependent adenoviral vector. Hum Gene Ther 15: 145-156.

Ehrhardt A, Kay MA (2002) A new adenoviral helper-dependent vector results in long-term therapeutic levels of human coagulation factor IX at low doses in vivo. Blood 99: 3923-3930.

Ehrhardt A, Xu H, Kay MA (2003) Episomal persistence of recombinant adenoviral vector genomes during the cell cycle in vivo. J Virol 13: 7689-7695.

Eto Y, Gao JQ, Sekiguchi F, Kurachi S, Katayama K, Mizuguchi $\mathrm{H}$, Hayakawa T, Tsutsumi Y, Mayumi T, Nakagawa S (2004) Neutralizing antibody evasion ability of adenovirus vector induced by the bioconjugation of methoxypolyethylene glycol succimidyl propionate (MPEG-SPA). Biol Pharm Bull 27: 936-938.

Fleury S, Driscoll R, Simeoni E, Dudler J, von Segesser LK, Kappenberger L, Vassalli G (2004) Helper-dependent adenovirus vectors devoid of all viral genes cause less myocardial inflammation compared with first-generation adenovirus vectors. Basic Res Cardiol 99: 247-256.

Gerard RD, Chan L (1996) Adenovirus-mediated gene transfer: strategies and applications in lipoprotein research. Curr Opin Lipidol 7: 105-111.

Gerard RD, Collen D (1997) Adenovirus gene therapy for hypercholesterolemia, thrombosis and restenosis. Cardiovasc Res 35: 451-458.

Gilbert R, Dudley RW, Liu AB, Petrof BJ, Nalbantoglu I, Karpati G (2003) Prolonged dystrophin expression and functional correction of $\mathrm{mdx}$ mouse muscle following gene transfer with a helper-dependent (gutted) adenovirus-encoding murine dystrophin. Hum Mol Genet 12: 1287-1299.

Haecker SE, Stedman HH, Balice-Gordon RJ, Smith DBJ, Greelish JP, Mitchell MA, Wells A, Sweeney HL, Wilson JM (1996) In vivo expression of full-length human dystrophin from adenoviral vectors deleted of all viral genes. Hum Gene Ther 7: 1907-1914.

Hardy S, Kitamura M, Harris-Stansil T, Dai Y, Phipps ML (1997) Construction of adenovirus vector through crelox recombination. J Virol 71: 1842-1849.

Harui A, Suzuki S, Kochanek S, Mitani K (1999) Frequency and stability of chromosomal integration of adenovirus vectors. J Virol 73: 6141-6146.

Hillgenberg M, Tonnies H, Strauss M (2001) Chromosomal integration pattern of a helper-dependent minimal adenovirus vector with a selectable marker inserted into a 27.4-kilobase genomic stuffer. J Virol 75: 9896-9908.

Józkowicz A, Dulak J, Nanobashvili J, Prager M, Huk J (2002) Gutless adenoviral vectors - promising tools for gene therapy. Eur Surg 34: 95-100.

Kafri T, Morgan D, Krahl T, Sarvetnick N, Sherman L, Verma I (1998) Cellular immune response to adenoviral vector infected cells does not require de novo viral gene expression: implications for gene therapy. Proc Natl Acad Sci USA 95: 11377-11382.

Kim IH, Józkowicz A, Piedra PA, Oka K, Chan L (2001) Lifetime correction of genetic deficiency in mice with a single injection of helper-dependent adenoviral vector. Proc Natl Acad Sci USA 98: 13282-13287.

Kobayashi K, Oka K, Forte T, Ishida B, Teng B, Ishimura-Oka K, Nakamuta M, Chan L (1996) Reversal of hypercholesterolemia in low density lipoprotein receptor knockout mice by adenovirus-mediated gene transfer of the very low density lipoprotein receptor. J Biol Chem 271: 6852-6860. 
Kochanek S, Clemens PR, Mitani K, Chen HH, Chan S, Caskey CT (1996) A new adenoviral vector: replacement of all viral coding sequences with $28 \mathrm{~kb}$ of DNA independently expressing both full-length dystrophin and $\beta$-galactosidase. Proc Natl Acad Sci USA 93: 5731-5736 .

Kojima H, Fujimiya M, Matsumura K, Younan P, Imaeda H, Maeda M, Chan L (2003) NeuroD-betacellulin gene therapy induces islet neogenesis in the liver and reverses diabetes in mice. Nat Med 9: 596-603.

Kovesdi I, Brough DE, Bruder JT, Wickham TJ (1997) Adenoviral vectors for gene transfer. Curr Opin Biotechnol 8: 583-589.

Kreppel F, Kochanek S (2004) Long-term transgene expression in proliferating cells mediated by episomally maintained high-capacity adenovirus vectors. J Virol 78: 9-22.

Maione D, Wiznerowicz M, Delmastro P, Cortese R, Ciliberto G, La Monica N, Savino R (2000) Prolonged expression and effective readministration of erythropoietin delivered with a fully deleted adenoviral vector. Hum Gene Ther 11: 859-868.

Maione D, Della Rocca C, Giannetti P, D'Arrigo R, Liberatoscioli L, Franlin LL, Sandig V, Ciliberto G, La Monica N, Savino R (2001) An improved helper-dependent adenoviral vector allows persistent gene expression after intramuscular delivery and overcomes preexisting immunity to adenovirus. Proc Natl Acad Sci USA 98: 5986-5991 .

Mian A, McCormack WM Jr, Mane V, Kleppe S, Ng P, Finegold M, O'Brien WE, Rodgers JR, Beaudet AL, Lee B (2004) Long-term correction of ornithine transcarbamylase deficiency by WPRE-mediated overexpression using a helper-dependent adenovirus. Mol Ther 10: 492-499.

Mitani K, Kubo S (2002) Adenovirus as an integrating vector. Curr Gene Ther 2: 135-144.

Mitani K, Graham FL, Caskey CT, Kochanek S (1995) Rescue, propagation, and partial purification of a helper virus-dependent adenovirus vector. Proc Natl Acad Sci USA 95: 3854-3858.

Mok H, Palmer DJ, Ng P, Barry MA (2005) Evaluation of polyethylene glycol modification of first-generation and helper-dependent adenoviral vectors to reduce innate immune responses. Mol Ther 11: 66-79.

Morral N, Parks R, Zhou H, Langston C, Schiedner G, Quinones J, Graham FL, Kochanek S, Beaudet AL (1998) High doses of a helper-dependent adenoviral vector yield supra-physiological levels of alpha1-antitripsin with negligible toxicity. Hum Gene Ther 9: 2709-2716.

Morral N, O'Neal W, Rice K, Leland M, Kaplan J, Piedra PA, Zhou H, Parks RJ, Velji R, Aguilar-Cordova E, Wadsworth S, Graham FL, Kochanek S, Carey KD, Beaudet AL (1999) Administration of helper-dependent adenoviral vectors and sequential delivery of different vector serotype for long-term liver-directed gene transfer in baboons. Proc Natl Acad Sci USA 96: 12816$-12821$.

Morsy MA, Gu MC, Zhao JZ, Holder DJ, Rogers IT, Pouch WJ, Motzel SL, Klein HJ, Gupta SK, Liang X, Tota MR, Rosenblum CI, Caskey CT (1998a) Leptin gene therapy and daily protein administration: a comparative study in the ob/ob mouse. Gene Ther 5: 8-18.

Morsy MA, Gu MC, Motzel S, Zhao J, Lin J, Su Q, Allen H, Franlin L, Parks RJ, Graham FL, Kochanek S, Bett AJ, Caskey CT (1998b) An adenoviral vector deleted for all viral coding sequences results in enhanced safety and extended expression of a leptin transgene. Proc Natl Acad Sci USA 95: 7866-7871.
Mountain A (2000) Gene therapy: the first decade. Trends Biotechnol 18: 119-128.

Muruve DA, Cotter MJ, Zaiss AK, White LR, Liu Q, Chan T, Clark SA, Ross PJ, Meulenbroek RA, Maelandsmo GM, Parks RJ (2004) Helper-dependent adenovirus vectors elicit intact innate but attenuated adaptive host immune responses in vivo. J Virol 78: 5966-5972.

Ng P, Evelegh C, Cummings D, Graham FL (2002) Cre levels limit packaging signal excision efficiency in the Cre/loxP helper-dependent adenoviral vector system. J Virol 76: 4181-4189.

Nomura S, Merched A, Nour E, Dieker C, Oka K, Chan L (2004) Low-density lipoprotein receptor gene therapy using helper-dependent adenovirus produces long-term protection against atherosclerosis in a mouse model of familial hypercholesterolemia. Gene Ther 11: 1540-1548.

Oka K, Pastore L, Kim IH, Merched A, Nomura S, Lee HJ, Merched-Sauvage M, Arden-Riley C, Lee B, Finegold M, Beaudet A, Chan L (2001) Long-term stable correction of low-density lipoprotein receptor-deficient mice with a helper-dependent adenoviral vector expressing the very low-density lipoprotein receptor. Circulation 103: $1274-1282$

Oshima Y, Oshima S, Nambu H, Kachi S, Hackett SF, Melia M, Kaleko M, Connelly S, Esumi N, Zack DJ, Campochiaro PA (2004) Increased expression of VEGF in retinal pigmented epithelial cells is not sufficient to cause choroidal neovascularization. I Cell Physiol 201: 393-400.

Palmer DJ, Ng P (2005) Helper-dependent adenoviral vectors for gene therapy. Hum Gene Ther 16: 1-16.

Parks R, Chen L, Anton M, Sankar U, Rudnicki MA, Graham FL (1996) A helper-dependent adenovirus vector system: removal of helper virus by Cre-mediated excision of the viral packaging signal. Proc Natl Acad Sci USA 93: 13565-13570.

Parks RJ, Bramson JL, Wan Y, Addison CL, Graham FL (1999) Effects of stuffer DNA on transgene expression from helper-dependent adenovirus vectors. J Virol 73: 8027-8034.

Pastore L, Belalcazar LM, Oka K, Cela R, Lee B, Chan L, Beaudet AL (2004) Helper-dependent adenoviral vector-mediated long-term expression of human apolipoprotein A-I reduces atherosclerosis in apo E-deficient mice. Gene 327: 153-160.

Raper SE, Chirmule N, Lee FS, Wivel NA, Bagg A, Gao GP, Wilson JM, Batshaw ML (2003) Fatal systemic inflammatory response syndrome in a ornithine transcarbamylase deficient patient following adenoviral gene transfer. Mol Genet Metab 80: 148-158.

Raper SE, Wilson JM, Yudkoff M, Robinson MB, Ye X, Batshaw ML (1998) Developing adenoviral-mediated in vivo gene therapy for ornithine transcarbamylase deficiency. J Inherit Metab Dis 21 (Suppl 1): 119-137.

Recchia A, Parks RJ, Lamartina S, Toniatti C, Pieroni L, Palombo F, Ciliberto G, Graham FL, Cortese R, La Monica N, Colloca S (1999) Site-specific integration mediated by a hybrid adenovirus/adeno-associated virus vector. Proc Natl Acad Sci USA 96: 2615-2620.

Reddy PS, Sakhuja K, Ganesh S, Yang L, Kayda D, Brann T, Pattison S, Golightly D, Idamakanti N, Pinkstaff A, Kaloss M, Barjot C, Chamberlain JS, Kaleko M, Connelly S (2002) Sustained human factor VIII expression in hemophilia A mice following systemic delivery of a gutless adenoviral vector. Mol Ther 5: 63-73.

Sakhuja K, Reddy PS, Ganesh S, Cantaniag F, Pattison S, Limbach P, Kayda DB, Kadan MJ, Kaleko M, Connelly S (2003) Optimization of the generation and propagation of gutless adenoviral vectors. Hum Gene Ther 14: 243-254. 
Schiedner G, Bloch W, Hertel S, Johnston M, Molojavyi A, Dries V, Varga G, Van Rooijen N, Kochanek S (2003) A hemodynamic response to intravenous adenovirus vector particles is caused by systemic Kupffer cell-mediated activation of endothelial cells. Hum Gene Ther 14: 1631-1641.

Shi CX, Hitt M, Ng P, Graham FL (2002) Superior tissuespecific expression from tyrosinase and prostate-specific antigen promoters/enhancers in helper-dependent compared with first-generation adenoviral vectors. Hum Gene Ther 13: 211-224.

Shi CX, Long MA, Liu L, Graham FL, Gauldie J, Hitt MM (2004) The human SCGB2A2 (mammaglobin-1) promoter/enhancer in a helper-dependent adenovirus vector directs high levels of transgene expression in mammary carcinoma cells but not in normal nonmammary cells. Mol Ther 10: 758-767.

Soifer HS, Kasahara N (2004) Retrotransposon-adenovirus hybrid vectors: efficient delivery and stable integration of transgenes via a two-stage mechanism. Curr Gene Ther 4: 373-384.

Soifer H, Higo C, Kazazian HH, Moran JV, Mitani K, Kasahara N (2001) Stable integration of transgenes delivered by a retrotransposon-adenovirus hybrid vector. Hum Gene Ther 12: 1417-1428.

Soifer H, Higo C, Logg CR, Jih LJ, Shichinohe T, Harboe-Schmidt E, Mitani K, Kasahara N (2002) A novel, helper-dependent, adenovirus-retrovirus hybrid vector: stable transduction by a two-stage mechanism. Mol Ther 5: 599-608.

Soudais C, Skander N, Kremer EJ (2004) Long-term in vivo transduction of neurons throughout the rat CNS using novel helper-dependent CAV-2 vectors. FASEB J 18: 391-393.

Stilwell JL, McCarty DM, Negishi A, Superfine R, Samulski RJ (2003) Development and characterization of novel empty adenovirus capsids and their impact on cellular gene expression. J Virol 77: 12881-21885.

Takahashi K, Saishin Y, Saishin Y, Silva RL, Oshima Y, Oshima S, Melia M, Paszkiet B, Zerby D, Kadan MJ, Liau G, Kaleko M, Connelly S, Luo T, Campochiaro PA (2003) Intraocular expression of endostatin reduces VEGFinduced retinal vascular permeability, neovascularization, and retinal detachment. FASEB J 17: 896-898.

Toietta G, Pastore L, Cerullo V, Finegold M, Beaudet AL, Lee B (2002) Generation of helper-dependent adenoviral vectors by homologous recombination. Mol Ther 5 : 204-210.

Umana P, Gerdes CA, Stone D, Davis JR, Ward D, Castro MG, Lowenstein PR (2001) Efficient FLPe recombinase enables scalable production of helper-dependent ad- enoviral vectors with negligible helper-virus contamination. Nat Biotechnol 19: 582-585.

Wang Y, Huang S (2000) Adenovirus technology for gene manipulation and functional studies. Drug Disc Today 5: 10-16.

Wang L, Hernandez-Alcoceba R, Shankar V, Zabala M, Kochanek S, Sangro B, Kramer MG, Prieto J, Qian C (2004) Prolonged and inducible transgene expression in the liver using gutless adenovirus: a potential therapy for liver cancer. Gastroenterology 126: 278-289.

Wen S, Graf S, Massey PG, Dichek DA (2004) Improved vascular gene transfer with a helper-dependent adenoviral vector. Circulation 110: 1484-1491.

Wickham TJ, Mathias P, Cheresh DA, Numerow GR (1993) Integrins $\alpha \mathrm{v} \beta 3$ and $\alpha \mathrm{v} \beta 5$ promote adenovirus internalization but not virus attachment. Cell 73: 309-319.

Wilmott R, Amin RS, Perez CR, Wert SEM, Keller G, Boivin GP, Hirsch R, De Inocencio J, Lu P, Reising SF, Yei S, Whitsett JA, Trapnell BC (1996) Safety of adenovirusmediated transfer of the human cystic fibrosis transmembrane conductance regulator cDNA to the lungs of nonhuman primates. Hum Gene Ther 6: 301-318.

Yant SR, Ehrhardt A, Mikkelsen JG, Meuse L, Pham T, Kay MA (2002) Transposition from a gutless adeno-transposon vector stabilizes transgene expression in vivo. Nat Biotechnol 20: 999-1005.

Ye X, Robinson MB, Pabin C, Quinn T, Jawad A, Wilson JM, Batshaw ML (1997) Adenovirus-mediated in vivo gene transfer rapidly protects ornithine transcarbamylase-deficient mice from an ammonium challenge. Pediatr Res 41: 527-534.

Zerby D, Sakhuja K, Reddy PS, Zimmerman H, Kayda D, Ganesh S, Pattison S, Brann T, Kadan MJ, Kaleko M, Connelly S (2003) In vivo ligand-inducible regulation of gene expression in a gutless adenoviral vector system. Hum Gene Ther 14: 749-761.

Zhang HG, Zhou T, Yang P, Edwards CK III, Curiel DT, Moutz DM (1998) Inhibition of TNF $\alpha$ decreases inflammation and prolongs adenovirus gene expression in lung and liver. Hum Gene Ther 9: 1875-1884.

Zhou H, Zhao T, Pastore L, Nageh M, Zheng W, Rao XM, Beaudet AL (2001) A Cre-expressing cell line and an E1/E2a double-deleted virus for preparation of helperdependent adenovirus vector. Mol Ther 3: 613-622.

Zou L, Zhou H, Postore L, Yang K (2000) Prolonged transgene expression mediated by a helper-dependent adenoviral vector in the central nervous system. Mol Ther 2: 105-113.

Zou L, Yuan X, Zhou H, Lu H, Yang K (2001) Helper-dependent adenoviral vector-mediated gene transfer in aged rat brain. Hum Gene Ther 12: 181-191. 